\title{
CONFIGURAÇÃO SOCIOAMBIENTAL DA BACIA HIDROGRÁFICA DO RIO SUBAÉ
}

\author{
Sandra Freitas Santos ${ }^{(a)}$, Josefa Eliane Santana de Siqueira Pinto ${ }^{(b)}$ \\ (a) Estudante de mestrado do Programa de Pós-Graduação em Geografia/ Universidade Federal de Sergipe, \\ sandra.estroges@gmail.com \\ (b) Professora Dra. do Programa de Pós-Graduação em Geografia/Universidade Federal de Sergipe, \\ josefaeliane@ufs.br
}

\section{EIXO: BACIAS HIDROGRÁFICAS E RECURSOS HÍDRICOS: ANÁLISE, PLANEJAMENTO E GESTÃO}

\section{Resumo}

O processo de desequilíbrio entre sociedade e natureza contribui para o desencadeamento de problemas de ordem ambiental em decorrência, na maioria das vezes, do acelerado aumento do consumo, da falta de planejamento e de gestão socioambiental que respeite as fragilidades do meio ambiente, bem como proporcione uma melhor qualidade de vida para a população. Pensando assim, que a escolha pelo estudo das Bacias Hidrográficas surge como possibilidade de compreender, de forma integrada, a dinâmica natural dos aspectos físicos e antropogênicos do Rio Subaé. A escolha por esta escala espacial deve-se ao fato de serem identificados vários processos de uso e ocupação da terra, especialmente com destaque ao componente urbano que se sobressai pela forte intensidade, principalmente no alto curso. Assim, diversas intervenções são identificadas nessas áreas, sendo estas domésticas, industriais e agrícolas.

Palavras chave: Bacia Hidrográfica, Sociedade,Natureza e Dinâmica Socioambiental

\section{Introdução}

$\mathrm{O}$ processo de desequilíbrio entre sociedade e natureza contribui para o desencadeamento de problemas de ordem ambiental em decorrência, na maioria das vezes, do desenfreado consumo e da falta de um planejamento socioambiental que respeite às fragilidades do meio ambiente, bem como proporcione melhores condições de vida para a população.

Esse tipo de reflexão é considerado recente pelos teóricos, tendo em vista que com o fim da Segunda Guerra Mundial emergiram propostas, reflexões, sobre a situação ambiental do Planeta, bem como a compreensão de que os recursos naturais são finitos e que por isso deveriam ser utilizados com racionalidade. Nessa condição, movimentos ambientalistas destacaram-se por exigir limites para a utilização de tais elementos, o que provou uma reunião emblemática em Estocolmo em 1972, convocada pela Organização das Nações 
Unidas (ONU) a fim de debater, traçar metas, apesar das diversas contradições apresentadas por tais líderes mundiais.

Esse modelo de capitalismo que impulsiona a lógica produtiva acelerada como forma de ampliação da massa lucro, está talvez no cerne desta questão. E assim, na busca por atender à demanda crescente de matérias-primas, fontes de energia e novos espaços para a especulação imobiliária, o sistema produtivo apodera-se dos recursos naturais, mudando a face do planeta, dia após dia, redesenhando as paisagens e modificando sobremaneira o cenário natural.

O processo de apropriação dos recursos naturais é universal e quanto mais avança as novas tecnologias, mais rápido esse processo se torna. Configura um caminho irreversível que consome grande quantidade de áreas, muitas delas, ecossistemas frágeis e extremamente importantes para a manutenção do equilíbrio ecológico local e até regional. A degradação ambiental não pode ser entendida como uma consequência inerente aos atos do ser humano ou da civilização faz-se necessário buscar as causas concretas dessa degradação.

Nesta perspectiva, o presente trabalho tem por objetivo configurar a dinâmica socioambiental da Bacia Hidrográfica do Rio Subáe, sendo este um estudo pertinente quando se evidencia o quanto é antigo o processo de ocupação dessa área e à forte influência da urbanização sobre as suas nascentes. Sendo assim, o referencial teórico presente neste artigo abarca a discussão do conceito de bacia hidrográfica, como unidade ideal para os estudos integrados, propícios para o gerenciamento e gestão ambiental. Então, é importante ressaltar que este artigo é fruto do desenvolvimento do mestrado.

\section{Material e Métodos}

O primeiro procedimento metodológico adotado para o desenvolvimento deste trabalho consistiu no levantamento de referências bibliográficas para embasar a discussão teórica abordada. Fizeram-se necessárias algumas leituras de temas específicos que envolvessem as temáticas: Bacias Hidrográficas, Dinâmica Socioambiental, Sociedade e Natureza. Nesta perspectiva, as leituras de autores como: BOTELHO, R. G. M. 2004, MACHADO, P.J. 2012; SACRAMENTO, M. F. 2006, entre outros, contribuíram para 
esclarecer e fundamentar questões relacionadas às dinâmicas naturais desempenhadas na rede de drenagem, bem com a influência do processo de urbanização no seu alto curso.

Posteriormente para a obtenção dos resultados foi necessário, a utilização do Sistema de Informações Geográficas (SIG), que forneceu dados cartográficos para serem utilizados no programa Arcgis 10, com o propósito de obter os mapas temáticos, como isoietas, geologia e uso e ocupação da Terra, entre outros. No entanto, é importante ressaltar que foram realizadas atividades de campo a fim de verificar as informações apresentadas. Sendo assim, tais procedimentos foram fundamentais para a obtenção da análise desejada.

\section{Resultados}

Segundo Christofoletti (1980), os rios são considerados canais de escoamento de água que podem apresentar um fluxo mais ou menos caudaloso dependendo primordialmente dos fatores climáticos que interferem na dinâmica do ciclo hidrológico (manutenção hídrica em todo o ambiente) e nos mecanismos de distribuição das águas superficiais e subterrâneas através do escoamento que alimentam direta e indiretamente a drenagem.

Sua principal função está relacionada com o transporte de sedimentos das áreas mais elevadas para as mais baixas e dos continentes para o mar, erosão e deposição (BOTELHO, 2011). Fato que permite considerá-lo um sistema aberto, e como tal estabelece relações com elementos e fatores físicos e bióticos do seu meio, á exemplo do clima, rocha, solo, cobertura vegetal, entre outros. No entanto, analisá-lo isoladamente, rio pelo rio, não oferece condições para um estudo detalhado da dinâmica complexa que o envolve (SACRAMENTO; REGO, 2006).

Por esse motivo, a bacia hidrográfica emerge nos estudos da Geografia Física e das Ciências Ambientais como possibilidade de ofertar um estudo sistêmico voltado ao diagnostico, planejamento e gestão ambiental dos recursos hídricos. Nestas condições, alguns termos foram elaborados para representar tal integração, são estes: "unidade de gestão da paisagem", "unidade espacial", "unidade territorial", bem como "célula básica de análise ambiental" (BOTELHO; SILVA, 2004) sendo que, essas expressões evidenciam a importância que a unidade alcançou em meio a uma sociedade relapsa com os seus recursos hídricos. 
Conceituar bacia hidrográfica também perpassa por definições, mostrando-se certa coerência entre as mesmas. Sendo assim, Pires et. al. (2002, p.17) define-a, como "o conjunto de terras drenadas por um corpo d'água principal e seus afluentes e representa a unidade mais apropriada para o estudo qualitativo e quantitativo do recurso água e dos fluxos de sedimentos e nutrientes".

Na compreensão sistêmica, Rodrigues e Adami (2005) apud Machado e Torres (2012, p.40) abordam tal discussão afirmando que a rede de drenagem "como um sistema que compreende um volume de materiais, predominantemente sólidos e líquidos, próximo à superfície terrestre, delimitado interno e externamente por todos os processos que, a partir do fornecimento de água pela atmosfera, interferem no fluxo de matéria e de energia de um rio ou de uma rede de canais fluviais".

Considerando a possibilidade de avaliar o ambiente através da bacia hidrográfica, a definição apresentada por Pires et. al. (2002) "consiste na determinação de um espaço físico funcional, sobre o qual devem ser desenvolvidos mecanismos de gerenciamento ambiental na perspectiva do desenvolvimento sustentável (utilização, conservação de recursos hídricos)".

Por conseguinte, o estudo integrado só se efetiva se houver a compreensão dos componentes que envolvem os sistemas hídricos (solo, água, ar, vegetação) e dos processos que estão relacionados (infiltração, escoamento, erosão, assoreamento, inundação, contaminação). A partir desse diagnostico, pode-se avaliar o estado de equilíbrio dinâmico deste ambiente e assim propor ações de preservação e recuperação da área. Este direcionamento dado pelo estudo de bacias hidrográficas projeta níveis de qualidade ambiental que abarcam não somente aspectos físico-bióticos, como também os elementos socioeconômicos que estão essencialmente entrelaçados à qualidade de vida das populações (BOTELHO; SILVA, 2004).

A Bacia Hidrográfica do Rio Subaé (BHRS) possui $651 \mathrm{Km}^{2}$ de área, pertence a Região de Planejamento e Gestão das Águas (RPGA) do Recôncavo Norte, a qual abarca uma população de 286.428 habitantes residentes na zona rural e urbana (IBGE, 2010). Inserida em dois territórios de identidade: Portão do Sertão e Recôncavo Baiano, os quais contemplam parcialmente os municípios de Feira de Santana, Conceição do Jacuípe e São Gonçalo dos Campos, caracterizando o seu alto curso; Amélia Rodrigues e Santo Amaro, no médio curso; 


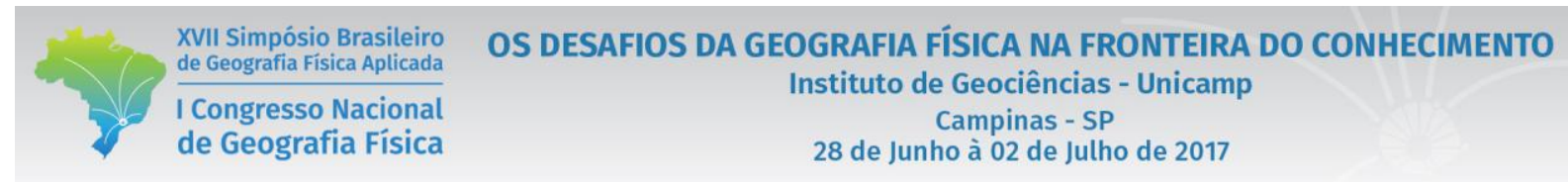

e, Santo Amaro, São Francisco do Conde e São Sebastião do Passé, no baixo curso. A Figura 1 apresenta a localização dessa Bacia Hidrográfica no âmbito dos municípios baianos que a rede de drenagem se encontra.

Figura 1- Mapa de localização da Bacia Hidrográfica do Rio Subaé

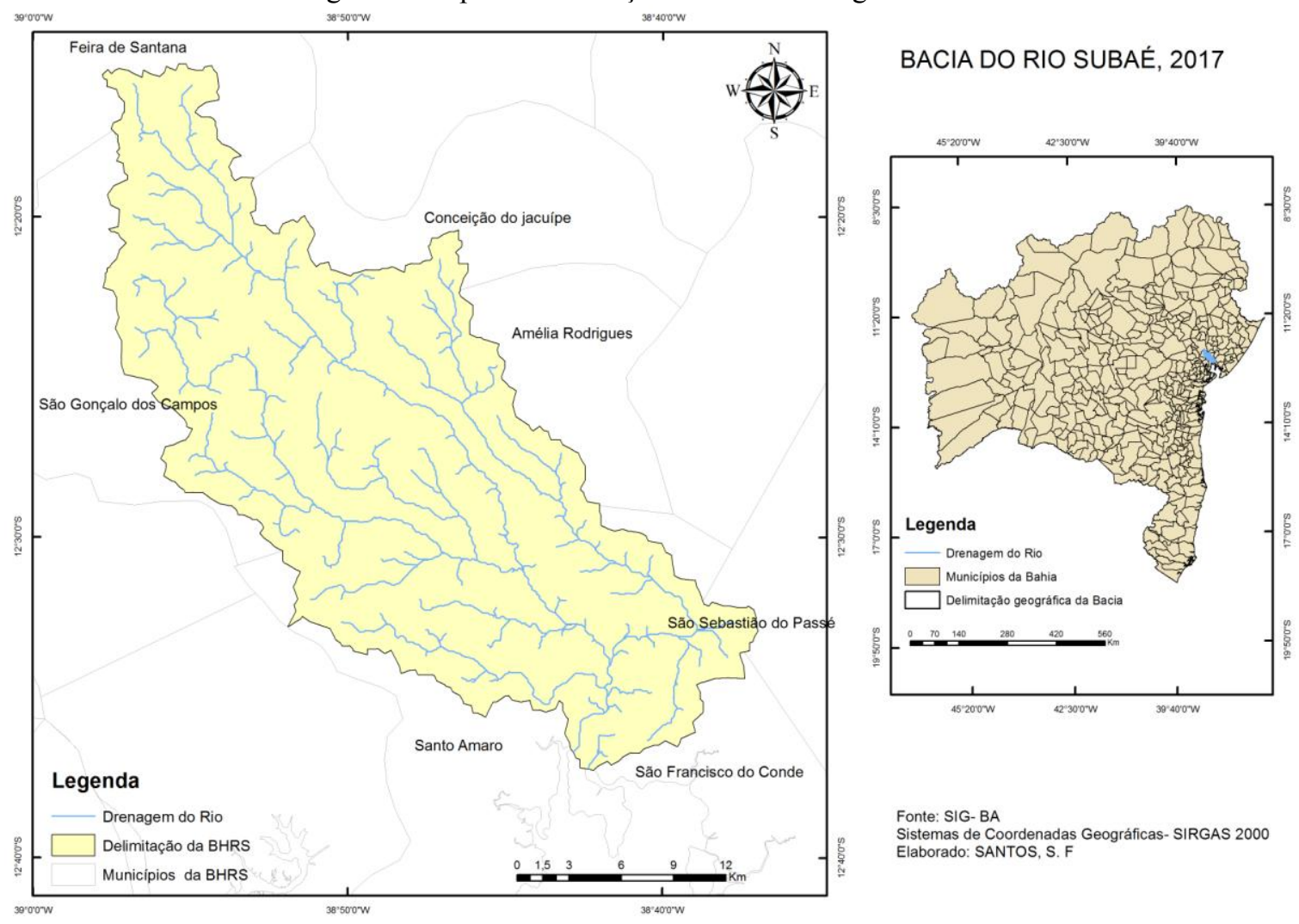

Dessa forma, a área de estudo apresenta diversidade dos seus condicionantes geoambientais, os quais são percebidos através dos estudos do clima, geologia, geomorfologia, solos, vegetação e das atividades antropogênicas, principalmente direcionados aos danos ambientais provocados pelo alto índice de antropização identificado no espaço.

Na BHRS encontram-se, no seu alto curso, uma faixa de transição climática, conhecido como agreste baiano, onde o clima varia de seco a subúmido, com pluviosidade média entre 900 a $1000 \mathrm{~mm}$. No médio curso, evidencia-se o aumento da pluviosidade caracterizando-o, como região que varia do subúmido a úmido, chegando a alcançar a média anual de 1500 mm de precipitação. No baixo curso, foz do Rio Subáe, o clima é úmido com média de $1700 \mathrm{~mm}$ ao ano como apresentado na figura 2. 


\section{OS DESAFIOS DA GEOGRAFIA FÍSICA NA FRONTEIRA DO CONHECIMENTO \\ Instituto de Geociências - Unicamp \\ Campinas - SP \\ 28 de Junho à 02 de Julho de 2017}

Figura 2. Isoietas anuais médias da Bacia do Rio Subaé

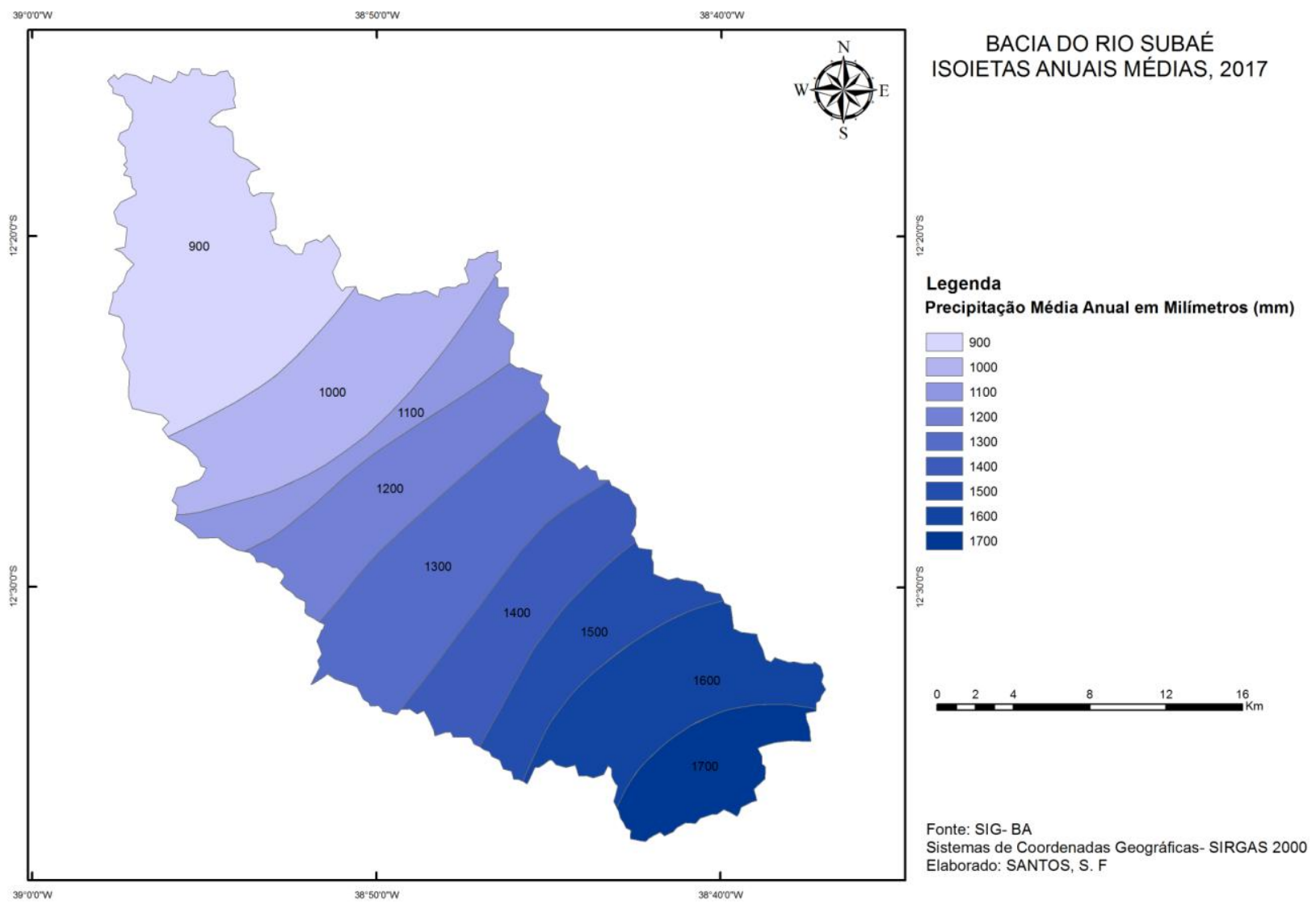

No que diz respeito aos aspectos geológicos, Motta (2015) afirma que esta bacia é formada por várias unidades litológicas que variam do Arqueano ao Quartenário, ou seja, concentram-se rochas antigas, as quais representam parte do complexo Santa-Luz e sedimentos mais recentes encontrados com prediminância na foz do Rio Subaé em decorrência de ser uma área de estuário. São identificadas três unidades geomorfológicas: (1) Bacia sedimentar do Recôncavo-Tucano, no qual o relevo possui topos aplanados e bordas desniveladas. Apresenta-se com predominância do médio ao baixo curso da bacia; (2) Depressões periféricas e interplanáliticas são feições de topos planos e enconstas convexas que abarca parte do alto e médio cursos; e o (3) Planalto Pré-Litorâneo constituido por rochas sedimentares datadas do quartenário arenosos, sílticos e lamosos (BORGES, et al, 2014).

A vegetação predominante é a Mata Atlantica, a qual na atualidade corresponde a somente 5\% da área da bacia hidrográfica, segundo Motta (2015). Isso ocorre em decorrência 
do intenso processo de antropização. Ocorrem também, no alto curso vestigios de vegetação de Caatinga nas áreas das nascentes do Rio localizadas no município de Feira de Santana e no baixo curso, faixas de manguezais que estão inseridas em parte do município de Santo Amaro e São Francisco do Conde.

No que corresponde aos solos, a Bacia Hidrográfica do Rio Subaé apresenta uma diversidade litológica, evidenciada na figura 3.

Figura 3. Mapa Litológico da Bacia do Rio Subaé.

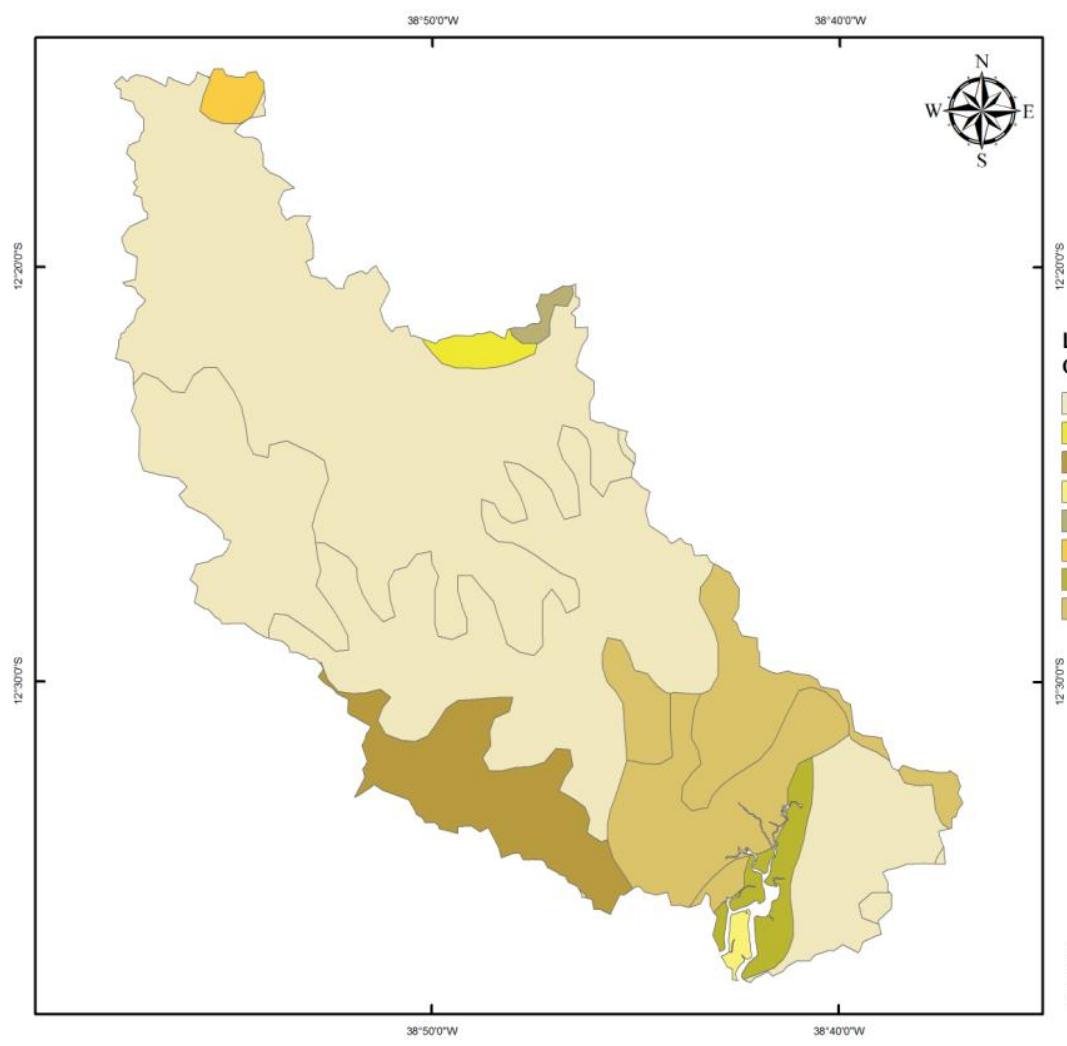

BACIA DO RIO SUBAÉ LITOLÓGICO, 2017

Classes Litológicas

ARGISSOLO VERMELHO-AMARELO Distrófico - PVAd ARGISSOLO VERMELHO-AMARELO Eutrófico - PVAE LATOSSOLO AMARELO Distrófico - LAd NEOSSOLO QUARTZARÊNICO - RQ NEOSSOLOS LITÓLICOS Eutróficos - RLE PLANOSSOLO HÁPLICO Eutrófico solódico - SXen TIPOS DE TERRENO

VERTISSOLOS - $V$

onte: SIG- BA Sistemas de Coordenadas Geográficas- SIRGAS 2000 Elaborado: SANTOS, S.F

A maior predominância é do Argissolo Vermelho-Amarelo Distrófico caracerizado por ser um solo bem desenvolvido, com alto teor de argila e pobre em nutrientes. Outro tipo de solo é o Latossolo Amarelo Distrófico, solos geralmente encontrados em áreas de vegetação de floresta e de campo cerrado, o qual possui como característica uma tendência a acidez e baixa fertilidade natural. No entanto, (GUERRA, A, J, T; BOTELHO, R, G, M, 2006) afirmam que este tipo de solo de modo geral, apresenta resistência aos processos ersosivos. Isso ocorre em decorrência da boa permeabilidade e drenabilidade apresentada 
XVII Simpósio Brasileiro de Geografia Fisica Aplicada

I Congresso Nacional de Geografia Física
OS DESAFIOS DA GEOGRAFIA FÍSICA NA FRONTEIRA DO CONHECIMENTO

Instituto de Geociências - Unicamp

Campinas - SP

28 de Junho à 02 de Julho de 2017

nesse tipo de solo. Encontram-se no baixo curso os Neossolo Quartzarêneo e o Neossolo Litólico Eutofríco ambos considerado solos pobres, com alto teor de areia e pouco desenvolvido. Como também tem-se a presença do vertissolo, localizado no baixo curso, esse solo apresenta concentração de argila, solos moderamente drenados e poucos profundos.

A ocupação da área de estudo é antiga, desde o período colonial, sob forte pressão das atividades açucareiras, e atualmente sofre com os intensos processos da industrialização. A figura 3 apresenta os diversos usos e ocupações identificados na bacia e que vem alterando significativamente a dinâmica físico/biótica desse sistema, principalmente no alto curso, local onde se concentram as nascentes do manancial.

Figura 3. Uso e ocupação da Terra da Bacia do Rio Subaé.

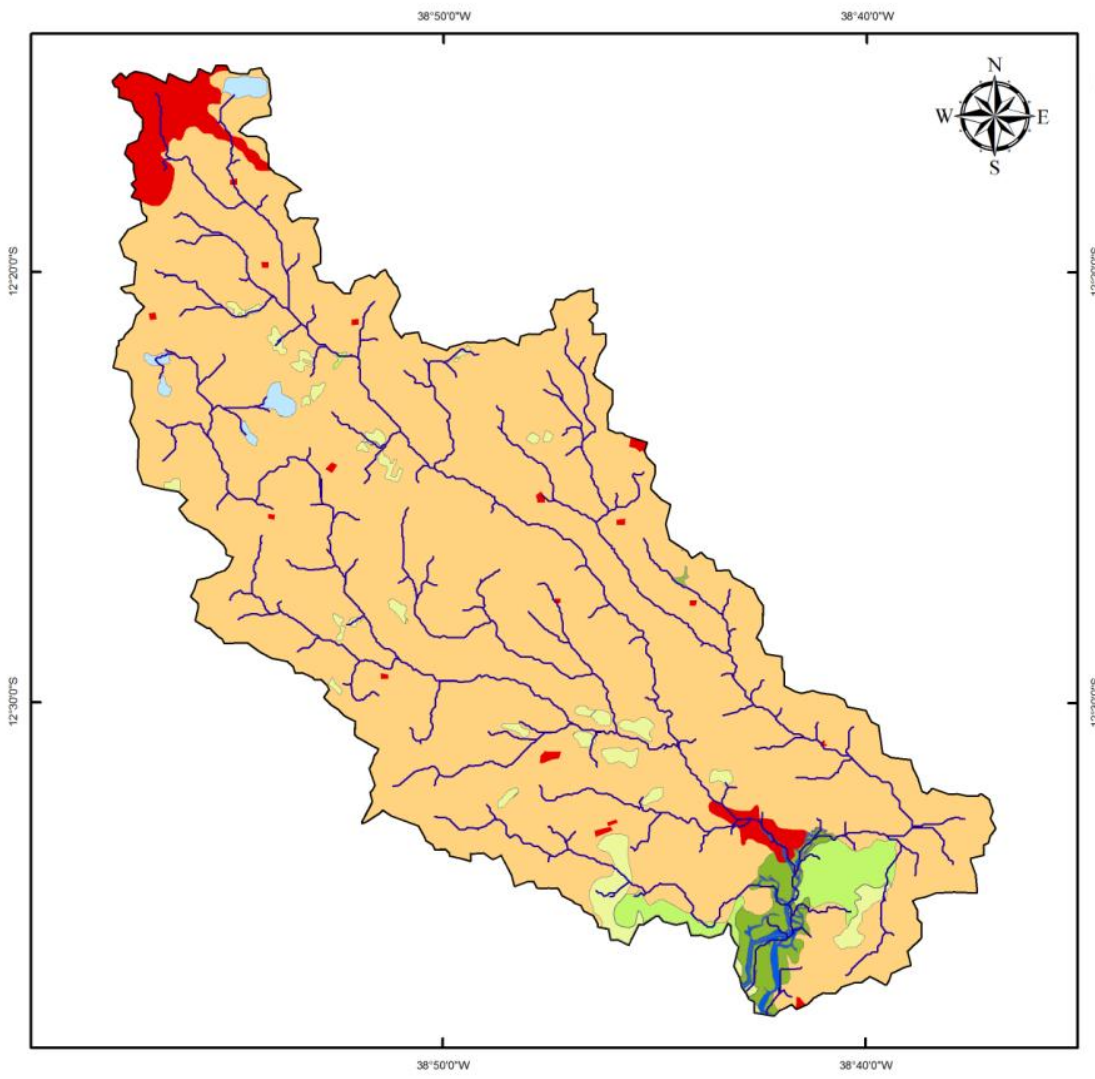

BACIA DO RIO SUBAÉ USO E OCUPAÇÃO DA TERRA, 2017

\section{Legenda}

Rio Subaé

Agricultura/Pecuária

Curso D'Água

Floresta Estacional

Floresta Secundária

Lago, Açude, Represa

Mangue

Reflorestamento

Área Urbana

$\square$ Bacia Hidrográfica do Rio Subaé

onte: SIG- BA

Sistemas de Coordenadas Geográficas- SIRGAS 2000 Elaborado: SANTOS, S. F

Estudos dessa área dão enfoque ao uso e ocupação da terra, principalmente os direcionados a qualidade da água. Esse direcionamento não ocorre por acaso, segundo Motta (2015) por volta de 33 anos, entre os anos de 1956 e 1993, atividades metalúrgicas de tratamento de minério de chumbo contaminaram o ar, solos e o Rio Subaé, nos seus diversos 


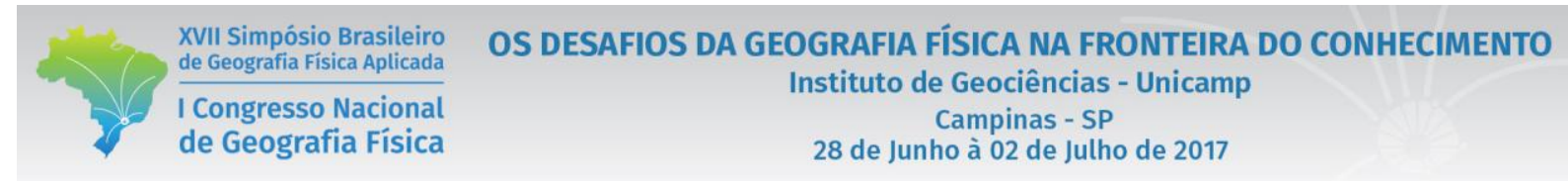

ambientes: natural, rural e urbano do município de Santo Amaro. Esse fato marcou consideravelmente a vida dos moradores desse município, os quais ainda hoje sofrem as consequencias dos impacto ambientais.

Seguindo a classificação do mapa, são identificados na área de estudo, formas diferentes de uso e de aspectos do solos. No alto curso apresenta-se a consentração da área urbana, local que posssui intensas atividades antropogênicas sobre as nascentes do Rio Subaé, na forma de grandes corpos d'água na área urbana da cidade de Feira de Santana. E com a instalação do Centro Industrial do Subaé (CIS) a partir de 1970 e a falta de políticas de preservação desses locais fortemente ameaçados, gestores públicos, instituições privadas e a comunidade civil feirense colocam em risco todo o curso do rio, como expressado na figura 4.

Figura 4. Forte processo de antropização das nascentes do Rio Subaé

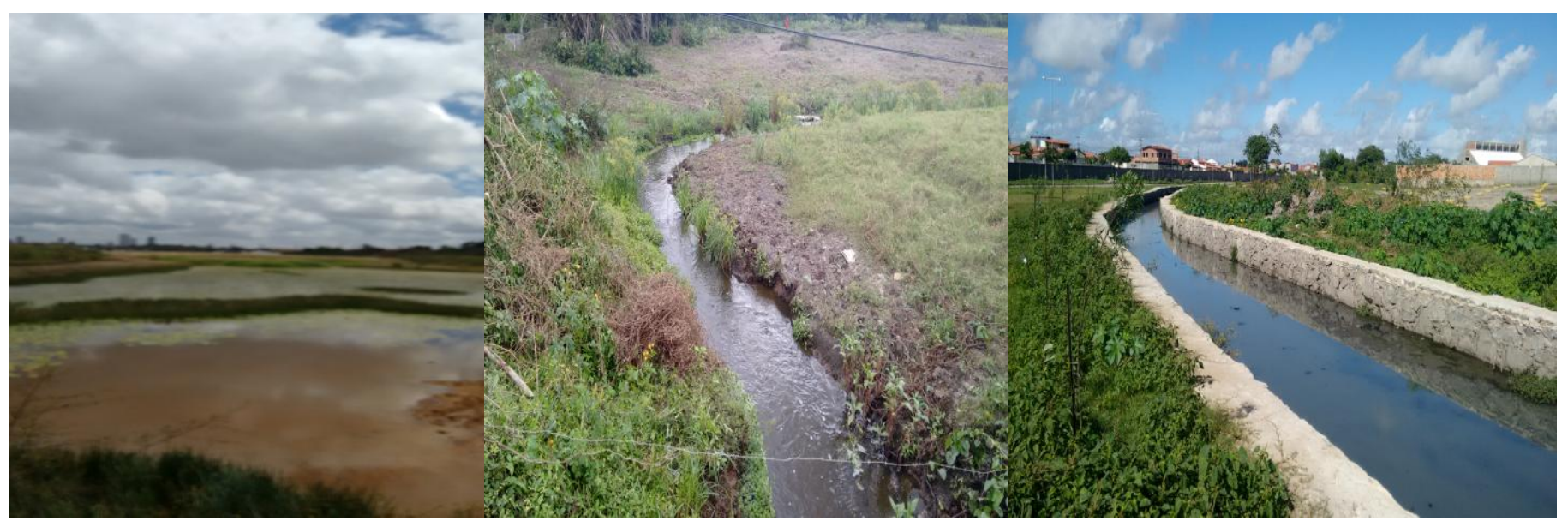

Fonte: Sandra Freitas Santos,2016.

Nesta perspectiva, ainda no alto curso, bem como em toda a bacia, as atividades da agricultura e pecuária são dominantes. Concentram-se atualmente o cultivo de hortaliças, frutiferas e mandioca. No que diz respeito a pecuária, o direcionamento é dado a carne bovina, favorecendo assim extensas áreas de pastagen, o que provoca problemas ao solo, como o processo de compactação, capacidade de infiltração da água, entre outros (BORGES, et al, 2014).

No médio ao baixo curso, são encontrados fragmentos de Florestas ombrófilas, geralmente ocupadas, com a intensão de expandir a lavoura da cana-de-açúcar, áreas de pastagens com o intuito de atender as demandas da agropecuária. No baixo curso, são identificadas com maior expressidade as terras úmidas, as quais seriam as faixas de manguezal, importante bioma 
que contribui significativamente para o sustento e comercialização local de pequenas comunidades (SANTOS, 2013).

\section{Considerações Finais}

Considerando a análise desenvolvida, percebe-se a urgência de estudos, que não só apresentem os danos causados pela ocupação e uso desmedido dos recursos naturais, como de análises que reforcem as potencialidades, recuperação e melhor gestão dessa bacia, ou seja, que a pense de forma integrada. Compreendê-la enquanto sistema favorecerá a elaboração de medidas reparadoras que busque um certo equilíbrio entre a natureza e sociedade local.

A Bacia Hidrográfica do Rio Subaé apresenta uma importância não só econômica, mas sobretudo cultural. Sua preservação e recuperação se configura como um resgate da história dos municípios que dela fazem parte e que tiveram o seu desenvolvimento atrelado ao recurso hídrico. A pesquisa gera indagações e curiosidades atreladas à necessidade de avanços além do campo acadêmico.

\section{Bibliografia}

BORGES, L. F. M. B. et al. Estudo de uso e ocupação da terra da bacia hidrográfica do rio Subaé- Estado da Bahia. Artigo. Instituto de Geociências/UFBA, 2014. Disponível em: http://www.cartografia.org.br/cbc/trabalhos/3/463/CT03-25_1403891286.pdf Acessado em; 07/03/2017.

BOTELHO, R. G. M.; SILVA, A. S. da. Bacia Hidrográfica e Qualidade Ambiental. In:VITTE, A. C.; Guerra, A. J. T. Reflexões Sobre a Geografia Física no Brasil. Rio de Janeiro: Bertrand Brasil, 2004, p.153-192.

BOTELHO, G. M; Bacias Hidrográficas Urbanas. In: BOTELHO, G. M .Geomorfologia urbana, Ed: Bertrand Brasil, 2011p. 71-115.

MACHADO, P.J. de Oliveira; TORRES, F. T. Pereira. Gestão de bacias e gerenciamento de recursos hídricos. In: Introdução à hidrogeografia, São Paulo: Cengage Learning, 2012.

MACHADO, P.J. de Oliveira; TORRES, F. T. Pereira. Bacia hidrográfica. . In: Introdução à hidrogeografia, São Paulo: Cengage Learning, 2012.

MOTTA, P. N. S. D. Bacia do rio Subaé, Bahia: características hidrográficas, geomorfológicas e hidroquímicas. Dissertação. Cruz das Almas-BA, 2015

SACRAMENTO, M. F; REGO, M. J. M. A bacia drenagem enquanto unidade integradora dos estudos ambientais; artigo, VI Simpósio Nacional de Geomorfologia; Goiânia, 2006.

RODRIGUEZ, J. M.M; SILVA, E. V. LEAL, A. C. Planejamento ambiental em Bacias hidrográficas. In: SILVA, Edson Vicente et al. Planejamento Ambiental e Bacias Hidrográficas.Ed. UFC, 2011.

SANTOS, L.T.S.de O. Análise da qualidade da água superficial do rio Subaé - Bahia e influência do uso e ocupação do solo em seu entorno. Dissertação. Universidade Estadual de Feira de Santana, 2013. 